\title{
Significant tsunami observed at ocean-bottom pressure gauges during the 2011 off the Pacific coast of Tohoku Earthquake
}

\author{
Takuto Maeda ${ }^{1,2}$, Takashi Furumura ${ }^{1,2}$, Shin'ichi Sakai ${ }^{2}$, and Masanao Shinohara ${ }^{2}$ \\ ${ }^{1}$ Center for Integrated Disaster Information Research, Interfaculty Initiative in Information Studies, The University of Tokyo, \\ 7-3-1 Hongo, Bunkyo-ku, Tokyo 113-0033, Japan \\ ${ }^{2}$ Earthquake Research Institute, The University of Tokyo, 1-1-1 Yayoi, Bunkyo-ku, Tokyo 113-0032, Japan
}

(Received April 7, 2011; Revised June 1, 2011; Accepted June 3, 2011; Online published September 27, 2011)

\begin{abstract}
The 2011 Tohoku Earthquake caused a devastating tsunami along the shoreline from the Tohoku to Kanto districts. Although many of the tide gauge stations along the Tohoku coast were saturated or damaged due to the tsunami, two cabled ocean-bottom tsunami sensors installed off Kamaishi successfully recorded the tsunami waveform just above the source rupture area. The records indicated a characteristic two-stage tsunami development sequence: a smoothly increasing tsunami amplitude from 0 to $2 \mathrm{~m}$ during the first $800 \mathrm{~s}$ from the earthquake origin time, and a short-period impulsive tsunami with a peak of more than $5 \mathrm{~m}$ in the following $200 \mathrm{~s}$. Such observations strongly suggest the lack of any sea floor upheaval at the stations during the earthquake, and the occurrence of an extremely large slip in the shallow portion of the subducting Pacific Plate near the trench axis. The source model derived from the offshore tsunami records indicates that a very large slip of $57 \mathrm{~m}$ occurred off Miyagi near the trench axis, south of the rupture area of the 1896 Meiji Sanriku tsunami earthquake, and was the major source of the highly destructive tsunami that subsequently developed.
\end{abstract}

Key words: The 2011 Tohoku Earthquake, tsunami, ocean bottom pressure gauges, tsunami simulation.

\section{Introduction}

On 11 March, 2011, a destructive $M_{\mathrm{w}} 9.0$ earthquake occurred off Miyagi, northeastern Japan, causing serious disasters associated with strong ground motions and large tsunamis. The global W-phase moment-tensor solution of the U.S. Geological Survey (USGS) showed a low-angle reverse fault along the interface of the subducting Pacific Plate with a seismic moment of $3.9 \times 10^{22} \mathrm{~N}$ m (U.S. Geological Survey, 2011). The USGS source model (Hayes, 2011) based on far-field waveform data suggests that the fault rupture area was about $550 \mathrm{~km}$ by $260 \mathrm{~km}$ within the northern Japan subduction zone. An unusually large tsunami with a height of more than $15 \mathrm{~m}$ hit the Sanriku coast of northern Japan, causing a significant number of casualties, estimated at more than 20,000 (National Police Agency, 2011). At present, the distribution of the maximum tsunami height along the Tohoku coast is still unclear since most of the tidal gauge stations in the Tohoku area became saturated above $9.3 \mathrm{~m}$ or were actually destroyed by the tsunami (Japan Meteorological Agency, 2011). A recent field tsunami survey reported that the maximum inundation height exceeded $40 \mathrm{~m}$ along the Sanriku coast (The 2011 Tohoku Earthquake Tsunami Joint Survey Group, 2011).

Offshore ocean-bottom pressure gauge (OBPG) stations, such as TM1 and TM2, located about $45-75 \mathrm{~km}$ from the Kamaishi coast, Tohoku, Japan, captured significant

Copyright (c) The Society of Geomagnetism and Earth, Planetary and Space Sciences (SGEPSS); The Seismological Society of Japan; The Volcanological Society of Japan; The Geodetic Society of Japan; The Japanese Society for Planetary Sciences; TERRAPUB.

doi:10.5047/eps.2011.06.005 tsunami waveforms just above the source rupture area before the tsunami hit the Tohoku coast (Fig. 1). The offshore tsunami records offer us a direct means of understanding the development of the tsunami due to slip associated with the large earthquake. In this paper, we study the peculiar source rupture process of the earthquake, which produced the extremely large tsunami along the Sanriku coast, by making use of the OBPG records obtained above the source rupture area. Also, we employ offshore tsunami records from the GPS buoy stations of the Deep-ocean Assessment and Reporting on Tsunami (DART) (Titov et al., 2005) to construct a tsunami source model to complement the OGPG data.

\section{OBPG Record Observed above the Fault}

Figure 1(b) shows OBPG tsunami traces recorded at stations TM1 and TM2 off Kamaishi, Northern Japan, operated by the University of Tokyo and Tohoku University (Hino et al., 2001). These OBPGs have a quartz-oscillator type pressure sensor with a dynamic range of $\pm 3000 \mathrm{~m}$ and a resolution of $0.5 \mathrm{~mm}$. The water depth at TM1 and TM2 is 1618 and $1013 \mathrm{~m}$, respectively, and the observed data is transmitted to land by fiber cable in real time. The records (Fig. 1(b)) showed that the tsunami already had a height of more than $5 \mathrm{~m}$ before it reached the coast.

The TM1 and TM2 records indicate a characteristic sea height change following the earthquake, indicating the propagation of a tsunami. Both traces (Fig. 1(b)) show a gradual uplift due to the tsunami following the highfrequency seismic waves, and a sudden uplift shortly afterwards. The tsunami record at TM1, located on the trench axis side, shows that the tsunami height increased gradually 
(a)
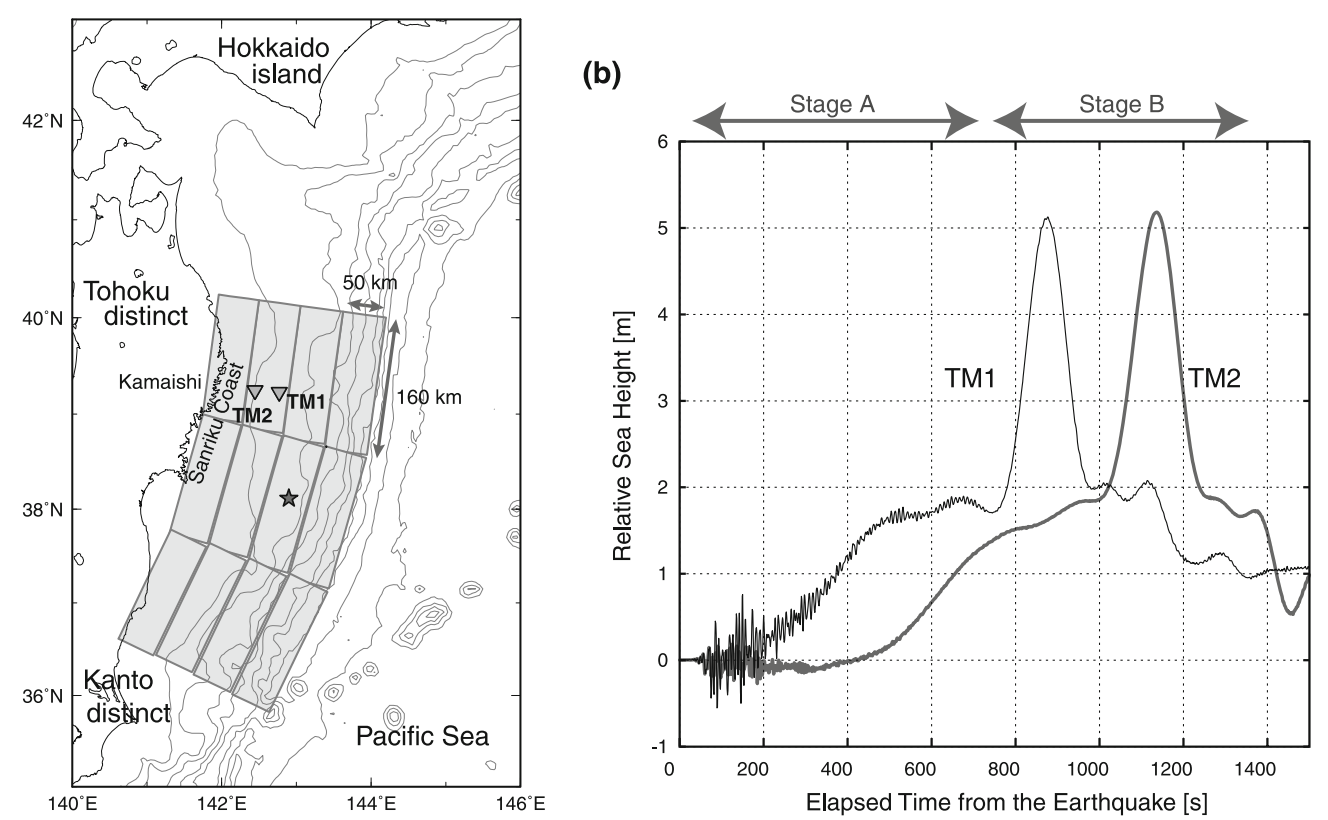

Fig. 1. (a) Index map showing the subfault geometries (gray rectangles) and OBPG stations TM1 and TM2 (triangles). Gray contour lines are bathymetry iso-depths at $1000 \mathrm{~m}$ intervals. The star indicates the epicenter location determined by the Japan Meteorological Agency. (b) Relative sea height trace recorded at TM1 (thin line) and TM2 (thick line) stations for the 2011 off the Pacific coast of Tohoku Earthquake.

from 0 to $1.8 \mathrm{~m}$ in the first $700 \mathrm{~s}$ following the earthquake (hereafter referred to as Stage A). This was followed by a very large, impulsive tsunami with a height of more than $3 \mathrm{~m}$ with a relatively short duration of approximately $150 \mathrm{~s}$ (Stage B). A similar waveform was observed at TM2 near the coast after a time lag of about $260 \mathrm{~s}$, which indicates an apparent tsunami wavespeed of $110 \mathrm{~m} / \mathrm{s}$. This wavespeed corresponds to an average water depth of $1235 \mathrm{~m}$ under the long-wavelength approximation, if the tsunami propagated parallel to the cable. This type of waveform is unique, and has not been observed in the OGPG records for the other earthquakes for such as the 2003 Off Tokachi $M_{\mathrm{w}} 8.0$ earthquake (e.g., Tsushima et al., 2009) or the 2004 SE Off Kii-Peninsula $M_{\mathrm{w}} 7.4$ earthquake (e.g., Saito and Furumura 2009). This suggests that a peculiar source rupture process may be associated with the earthquake that generated the severe tsunami. Discrepancies between the tsunami waveforms recorded at TM1 and TM2, such as the slight decrease in the tsunami height observed at TM2 200-400 s after the earthquake, accompanied by oscillations in the seismic wave, might provide other important constraints on the source rupture process of the earthquake.

\section{Tsunami Source Model}

We now consider an appropriate source model to explain the observed peculiar tsunami waveform at the two OBPG stations. We assume a source rupture area of approximately $480 \mathrm{~km}$ by $200 \mathrm{~km}$ over the subducting Pacific Plate as shown in Fig. 2(a), which is divided into $4 \times 3$ subfaults with lengths of $160-180 \mathrm{~km}$ and widths of $50 \mathrm{~km}$. The geometry of each subfault, such as its strike, dip, and depth is chosen to fit to the upper boundary of the subducting Pacific plate (e.g., Furumura and Kennett, 2005); the dip angles of the subfaults are set to 7,12,17, and 22 degrees from the trench axis side to the land and all rake angles are set to 86 degrees following the results of a W-phase moment-tensor inversion of the USGS (2011). The relative depths of each subfault from the ocean bottom are set to $3,9.09,19.49$, and 34.11 $\mathrm{km}$, from the trench to the land side.

The sea bottom elevation and initial sea height due to the slip over each subfault segment are calculated based on the analytic solution of Okada (1985), assuming a homogeneous half-space model with a Poisson ratio of 0.25 . The depth of each subfault is set relative to the ocean bottom rather than the sea surface. The Green's function of the tsunami waveform for a unit slip over each subfault is then calculated by a tsunami propagation simulation based on the linear long-wave theory (e.g., Goto, 1984). In this simulation, we use a 500-m resolution bathymetry model constructed by combining the ETOPO1 global Earth model and the J-EGG500 Japan coastal model for tsunami computation.

\subsection{Source slips and tsunami waveforms}

In order to explain the observed offshore tsunami at stations TM1 and TM2 shown in Fig. 1(b), we first examined the case of a uniform slip of $15 \mathrm{~m}$ over the entire $12 \mathrm{sub}$ fault segments and we calculated the co-seismic ground elevation above the source area and the tsunami waveform at TM1 and TM2.

The results for the ground surface deformation pattern and simulated tsunami waveforms at stations TM1 and TM2 are shown in Fig. 2(a). This demonstrates that a large upheaval of the seafloor occurs over the subfaults near the trench, with about 3-4 m uplift of the seafloor around TM1 and TM2. The resultant tsunami traces at TM1 and TM2 derived from the present simulation (inset of Fig. 2(a)) show a gradual fall in sea height from 0 to $-1 \mathrm{~m}$ at TM2, and to $-2 \mathrm{~m}$ at TM1 just after the earthquake (Stage A), followed 
(a)

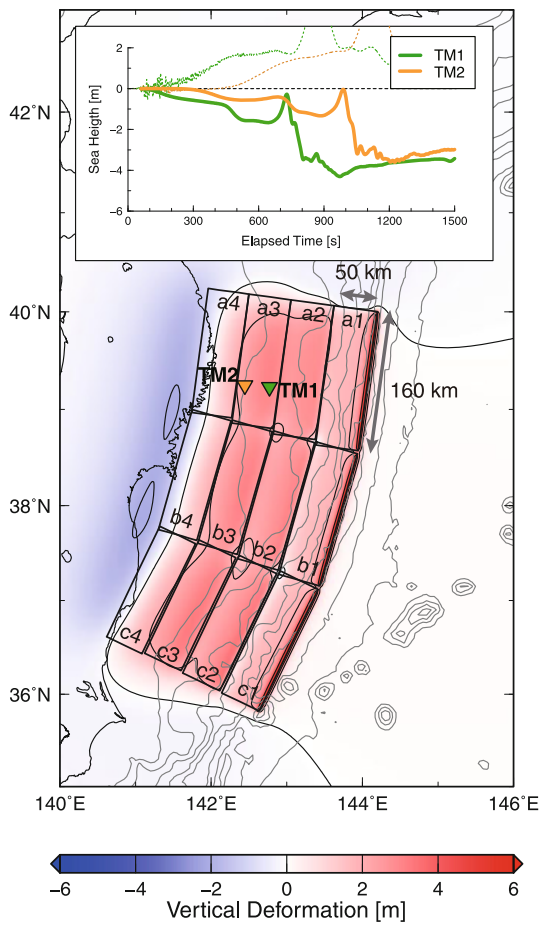

(b)

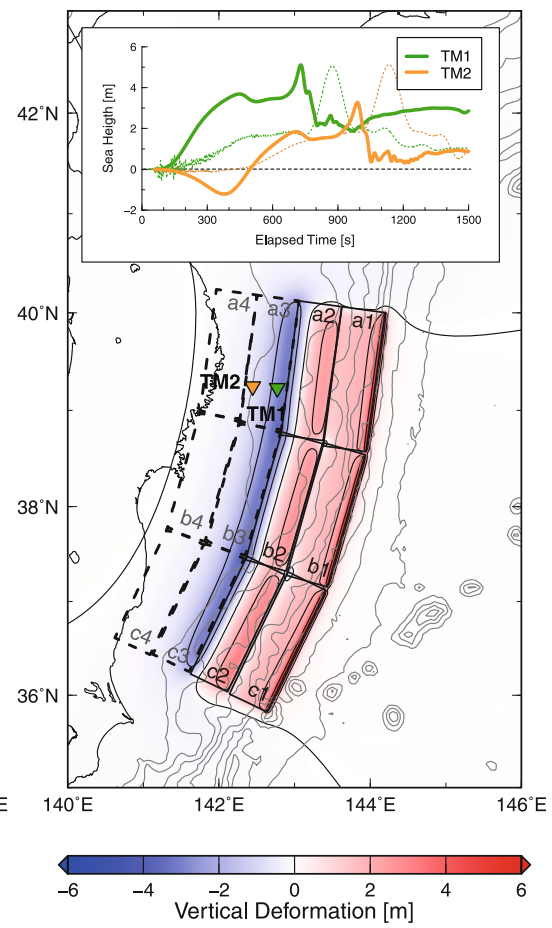

(c)

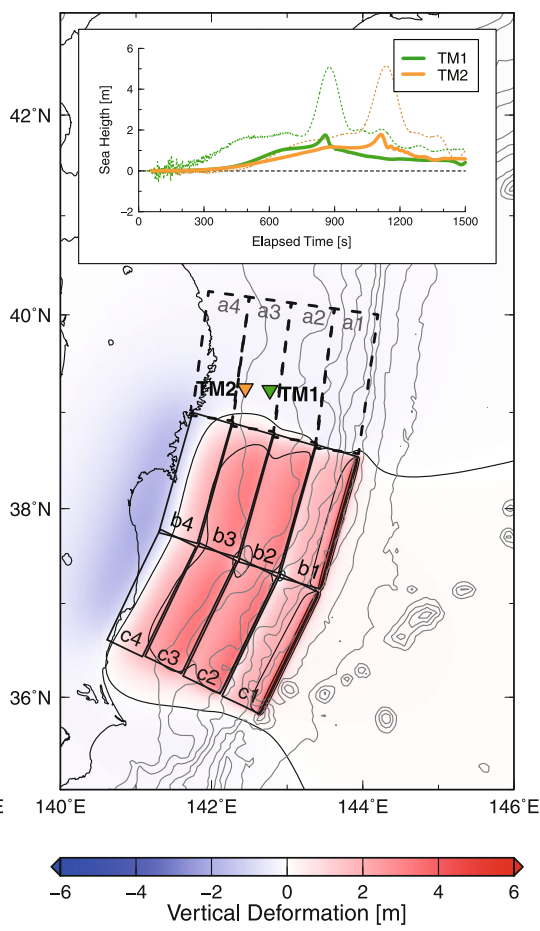

Fig. 2. Calculated vertical deformation of upheaval (red) and subsidence (blue) of ground surface due to a $15 \mathrm{~m}$ slip over the subfault plane and tsunami waveforms at stations TM1 (green) and TM2 (orange), for (a) uniform slip model, (b) shallow slip model, and (c) southern slip model. The observed tsunami traces (Fig. 1) are overlapped as dotted lines in each inset for comparison.

by a sudden drop of the sea surface to -3 to $-4 \mathrm{~m}$ at a later time (Stage B) at both stations. These characteristics of the simulated tsunami waveforms do not match those of the observed waveforms shown in Fig. 1(b). In this simulation, the large slip below TM1 and TM2 produce a large upheaval of the sea floor as well as the sea surface above TM1 and TM2 after the earthquake. An outflow of seawater at these stations occurs immediately after the coseismic deformation, which gradually reduces the sea level above TM1 and TM2 with increasing time. Therefore, the results of this model strongly suggest that very little sea bottom uplift occurred in the area around TM1 and TM2 during the earthquake.

Based on the above findings, we modified the source slip model to consider subsidence of the sea bottom in the area around TM1 and TM2. We assigned the same amount of slip $(15 \mathrm{~m})$ to the six shallower subfaults at the trench side (subfaults a1-2, b1-2, and c1-2), and no slip was assigned to the six deeper subfaults (Fig. 2(b)). The result based on this new source model revealed a subsidence of the sea bottom of $-4 \mathrm{~m}$ at TM1 and $-0.5 \mathrm{~m}$ at TM2. The simulated tsunami waveforms at TM1 and TM2 reproduced the observed features of the tsunami qualitatively well, including a gradual uplift of the sea surface from 0 to $4 \mathrm{~m}$ at TM1 following the earthquake in Stage A and a sudden uplift to $5 \mathrm{~m}$ in Stage B. Also, the shape of the simulated tsunami waveform agrees well with that observed at TM2, with a drop in sea height from 0 to $-1 \mathrm{~m}$ in the earlier part of Stage A, a gradual uplift due to the tsunami in the later part of Stage A, and a sudden uplift in Stage B (Fig. 1).

Although the modified source slip model shown in
Fig. 2(b) explains the observed features of the tsunami waveform at TM1 and TM2 reasonably well, the arrival time of the simulated large, short-wavelength tsunami in Stage B is much earlier than that actually observed. We therefore relocated the area of larger slip on the subfaults to the south (b1-4 and c1-4) in order to introduce a delay in the arrival time of the tsunami at TM1 and TM2 (Fig. 2(c)). After incorporating such a delay, the arrival times of the simulated tsunami at TM1 and TM2 were about 800 and $1100 \mathrm{~s}$ after the earthquake origin time, respectively, which shows good agreement with the observations. Thus, we found that the shape of the simulated tsunami waveform matches that of the observed tsunami for both stages. However, the maximum height of the simulated tsunami at TM1 and TM2 is only $2 \mathrm{~m}$. This indicates that a much larger slip is needed for subfault $\mathrm{b} 1$ and/or b2 in order to produce a tsunami with a height of more than $5 \mathrm{~m}$ at TM1 and TM2, as seen in the observational data (Fig. 1).

\subsection{Estimated slip distribution over the fault plane}

Based on these findings, we finally construct an appropriate tsunami source model to explain the observed tsunami waveforms at TM1 and TM2 by forward modeling (Fig. 3). The simulated tsunami waveforms reveal a gradual increase in the tsunami height from 0 to $2 \mathrm{~m}$ in the first $600 \mathrm{~s}$ after the earthquake (Stage A), which was mainly caused by slip at deeper parts of the plate interface (subfaults b3-4), and to some extent by a small amount of slip near the trench off Sanriku (a1-a2). The sudden increase of over $5 \mathrm{~m}$ in the height of the tsunami at $700 \mathrm{~s}$ (Stage B) was generated by a very large $(57 \mathrm{~m})$ slip over the subfault in the plate interface near the trench (b1-2). Our results suggest that no 
(a)

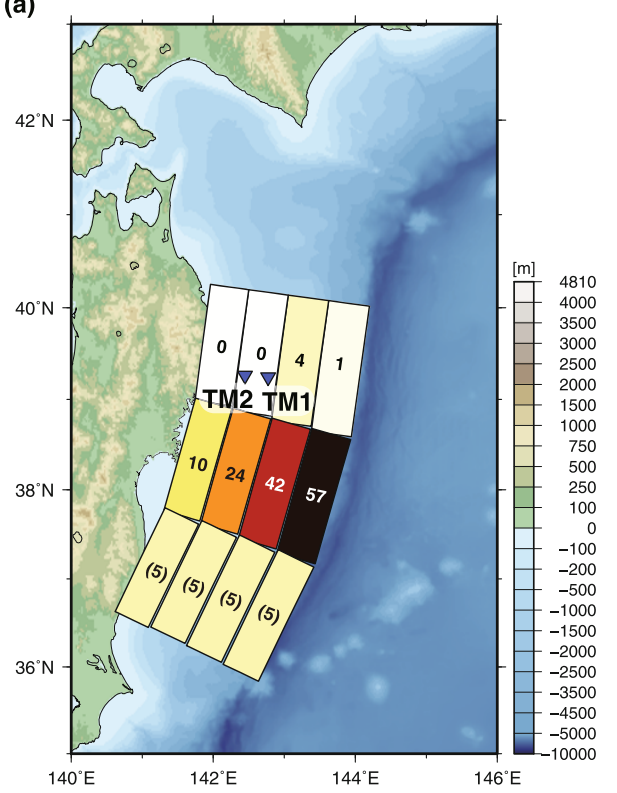

(b)

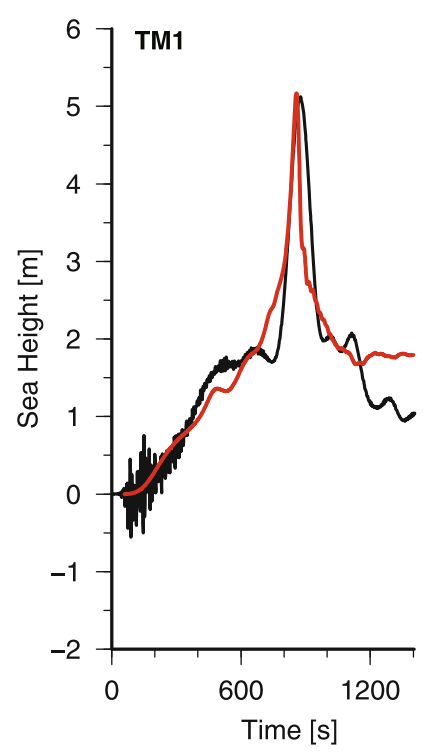

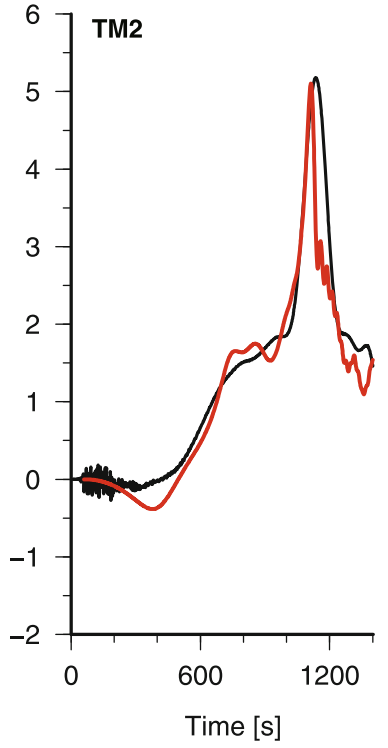

Fig. 3. (a) Estimated slip distribution in meters for each subfault. (b) Comparison of observed (black) and simulated (red) tsunami traces at stations TM1 and TM2. It should be noted that the slips on the southern subfaults are not well constrained from the records at TM1 and TM2.

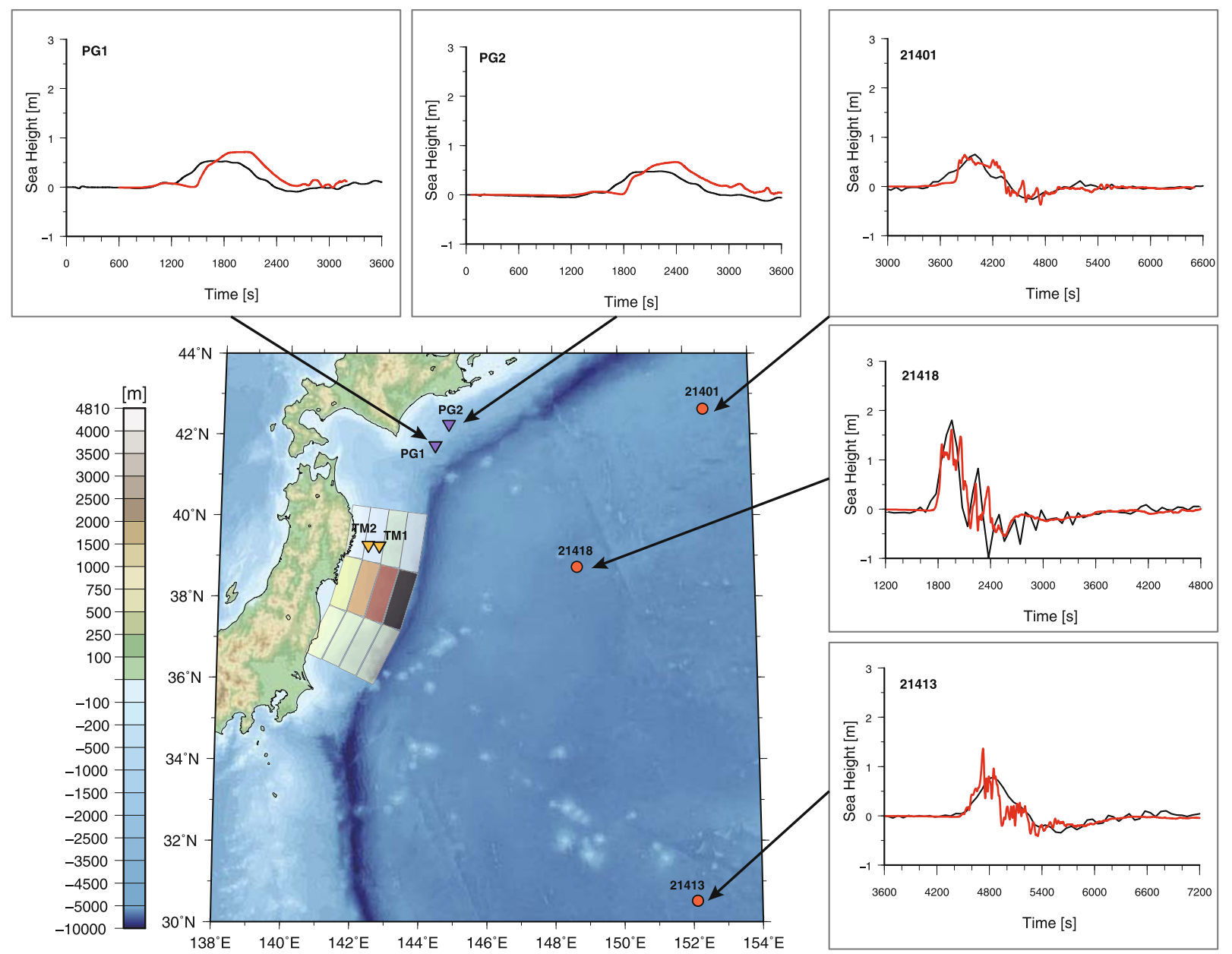

Fig. 4. Comparison of observed (black) and simulated (red) tsunami traces at each DART station (21401, 21418, 21413) and OBPGs off Kushiro (PG1, PG2). 
significant slip occurred over the northern segment of the subfault (a3-4), since the arrival times of the main tsunami at TM1 and TM2 are rather late at about 900 and $1100 \mathrm{~s}$, respectively, after the earthquake. We assumed that the slip over the southern segments (c1-4) is $5 \mathrm{~m}$; however, this slip cannot be well constrained by the tsunami records at TM1 and TM2.

In order to confirm the effectiveness of our tsunami source model based on only the tsunami records at TM1 and TM2 off Kamaishi, we compared our simulations with the tsunami waveforms at other DART stations (21401, 21413, 21418) in the Pacific Ocean and OBPGs off Kushiro (PG1 and PG2) (Fig. 4). Very good agreement is found between the simulated and observed tsunami waveforms at the three DART stations, although the arrival times of the simulated tsunami at stations PG1 and PG2 off Kushiro are somewhat later than those observed. This is because the length of the present subfault segment in the fault strike direction $(80 \mathrm{~km})$ is too large to provide efficient time resolution for tsunami propagation to PG1 and PG2 along the strike.

\section{Discussion and Conclusion}

The characteristics of the tsunami waveforms observed at two OBPG stations off Kamaishi during the 2011 off the Pacific coast of Tohoku Earthquake offers us a direct means for understanding the cause of the large tsunami generated by the earthquake. Forward modeling of the observed tsunami at OBPGs provided physical insights into the slip distribution of the fault. The gradual increase in the tsunami height following the earthquake (Stage A), and the subsequent sudden increase (Stage B) constrained the region of extremely large slip to the south of Kamaishi in the shallow portion of the plate interface (subfaults b1 and b2) near the trench axis, and very little slip occurred in the northern part near the coast (a3 and a4). Such characteristic features of tsunami waveforms observed just above the source rupture area cannot be detected in tsunami records at coastal stations such as tide gauge stations, because the tsunami trace of Stages A and B will coincide to form one large tsunami as it approaches the coast with a reduced propagation speed. In this study, we succeeded in utilizing the tsunami records from only two OBPG stations to estimate the shallow slip near the trench axis, but the extension of the source slip area could be more constrained if data from other OBPGs in the south were available.

The results of the present study indicate that very large slip at the shallower plate boundary near the trench produced a large, vertical ground deformation and a large, impulsive tsunami on the sea surface, which was the main cause of the large tsunami which hit the Sanriku coast. The area of large slip for the present tsunami source model is located just south of the source rupture area of the 1896 Meiji Sanriku tsunami earthquake (subfault a1 in Fig. 1) that caused 22,000 deaths, although nobody felt the ground shaking during the earthquake (e.g., Tanioka and Satake, 1996). In the case of the 2011 event, a complete slip from the shallow to the deeper plate boundary produced both large, prolonged ground motions and a tsunami as large as that of the 1896 event.

The large slip near the trench axis suggested by our study is consistent with those derived from teleseismic waveform data (Shao et al., 2011; Hayes, 2011; Ammon, 2011; Ide et al., 2011). However, the estimated slip of $57 \mathrm{~m}$ at the shallower plate boundary near the trench axis seems to be too large for a typical $M_{\mathrm{w}}$ 9.0-class earthquake, such as the 2004 Sumatra-Andaman earthquake (e.g., Fujii and Satake, 2007). At the moment, it is still unclear whether such a large slip actually occurred in the shallower plate boundary, or a comparable other mechanism, to develop the large vertical deformation of the seafloor which occurred during the earthquake. It is suggested that inelastic deformation resulting from a very soft sediment cover above the trench due to shallow-dipping slip over the plate interface could have enhanced the tsunami amplitude even for an ordinary slip on the plate interface (Tanioka and Seno, 2001; Seno and Hirata, 2007). Additionally, steeply-inclined fault systems cutting the sedimentary layers near the trench off Sanriku (Tsuru et al., 2002), such as the splay fault in the Nankai trough subduction zone (Park et al., 2002), may also cause a similar effect to the large slip of the plate boundary along the shallow plate interface near the trench.

Acknowledgments. We thank the Japan Agency for MarineEarth Science and Technology (JAMSTEC) for providing the realtime ocean-bottom pressure gauge data off Kushiro, and Pacific Marino Environmental Laboratory for providing DART data. We used bathymetry data J-EGG500 from the Japan Oceanographic Data Center and ETOPO1 from the National Geophysical Data Center. We also wish to thank Kazushige Obara, Yoshihiro Ito, Ken Tsuji, Hiroaki Tsushima, Hiroe Miyake, Simanchal Padhy, and Shinako Noguchi for fruitful discussions and valuable suggestions. We appreciate constructive comments from Kiyoshi Yomogida, Nick Horspool and an anonymous reviewer, which were very useful in helping us to improve the manuscript.

\section{References}

Ammon, C. J., T. Lay, and H. Kanamori, Seismicity animations, fault rupture model, etc. of the Great 2011 Tohoku-oki earthquake sequence, http://eqseis.geosc.psu.edu/ cammon/Japan2011EQ/, accessed 7 April 2011, 2011.

Fujii, Y. and K. Satake, Tsunami source of the 2004 Sumatra-Andaman earthquake inferred from tide gauge and satellite data, Bull. Seismol. Soc. Am., 97, S192-S207, 2007.

Furumura, T. and B. L. N. Kennett, Subduction zone guided waves and the heterogeneity structure of the subducted plate: Intensity anomalies in northern Japan, J. Geophys. Res., 110, doi:10.1029/2004JB003486, 2005.

Goto, C., Equation of nonlinear dispersive long waves for a large Ursell number, J. Hydraul. Coastal Environ. Eng., 351, 193-201, 1984 (in Japanese with English abstract).

Hayes, G., Finite fault model, updated result of the Mar 11, 2011 Mw 9.0 earthquake offshore Honshu, Japan, http://earthquake.usgs.gov/ earthquakes/eqinthenews/2011/usc0001xgp/finite_fault.php, accessed 7 April 2011, 2011.

Hino, R., Y. Tanioka, T. Kanazawa, S. Sakai, M. Nishino, and K. Suyehiro, Micro-tsunami from a local interplate earthquake detected by cabled offshore tsunami observation in northeastern Japan, Geophys. Res. Lett., 28(18), 3533-3536, doi:10.1029/2001GL013297, 2001.

Ide, S., A. Baltay, and G. C. Beroza, Shallow dynamic overshoot and energetic deep rupture in the $2011 \mathrm{Mw} 9.0$ Tohoku-Oki earthquake, Science Express, doi:10.1126/science.1207020, 2011

Japan Meteorological Agency, The 2011 off the Pacific coast of Tohoku earthquake, observed tsunami, http://www.jma.go.jp/ jma/en/2011_Earthquake/2011_Earthquake_Tsunami.pdf, accessed 19 May 2011, 2011.

National Police Agency (Japan), Damage situation and police countermeasures associated with 2011 Tohoku distinct-off the Pacific Ocean earthquake, May 19, 2011, http://www.npa.go.jp/ archive/keibi/biki/higaijokyo_e.pdf, accessed 19 May 2011, 2011. 
Okada, Y., Surface deformation due to shear and tensile faults in a halfspace, Bull. Seismol. Soc. Am., 75, 1135-1154, 1985.

Park, J.-O., T. Tsuru, S. Kodaira, P. R. Cummins, and Y. Kaneda, Splay fault branching along the Nankai subduction zone, Science, 297(5584), 1157-1160, doi:10.1126/science.1074111, 2002.

Saito, T. and T. Furumura, Three-dimensional simulation of tsunami generation and propagation: Application to intraplate events, J. Geophys. Res., 114, B02307, doi:10.1029/2007JB005523, 2009.

Seno, T. and K. Hirata, Did the 2004 Sumatra-Andaman earthquake involve a component of tsunami earthquakes?, Bull. Seismol. Soc. Am., 97(1A), 5296-5306, doi:10.1785/0120050615, 2007.

Shao, G., X. Li, C. Ji, and T. Maeda, Preliminary result of the Mar 11, $2011 \mathrm{Mw} 9.1$ Honshu earthquake, http://www.geol.ucsb.edu/ faculty/ji/big_earthquakes/2011/03/0311_v3/Honshu.html, accessed 7 April 2011, 2011.

Tanioka, Y. and K. Satake, Fault parameters of the 1896 Sanriku tsunami earthquake estimated from tsunami numerical modeling, Geophys. Res. Lett., 23(13), 1549-1552, doi:10.1029/96GL01479, 1996.

Tanioka, Y. and T. Seno, Sediment effect on tsunami generation of the 1896 Sanriku Tsunami Earthquake, Geophys. Res. Lett., 28(17), 3389-3392, doi:10.1029.2001GL013149, 2001.
The 2011 Tohoku Earthquake Tsunami Joint Survey Group, Tohoku earthquake tsunami information, http://www.coastal.jp/tsunami2011/, accessed 19 May 2011, 2011.

Titov, V. V., F. I. González, E. N. Bernard, M. C. Eble, H. O. Mojfeld, J. C. Newman, and A. J. Venturato, Real-time tsunami forecasting: Challenges and solutions, Nat. Hazards, 35, 35-41, doi:10.1007/s11069004-2403-3, 2005.

Tsushima, H., R. Hino, H. Fujimoto, Y. Tanioka, and F. Imamura, Nearfield tsunami forecasting from cabled ocean bottom pressure data, $J$. Geophys. Res., 114, B06309, doi:10.1029/2008JB005988, 2009.

Tsuru, T., J.-O. Park, S. Miura, S. Kodaira, Y. Kido, and T. Hayashi, Alongarc structural variation of the plate boundary at the Japan Trench margin: Implication of interplate coupling, J. Geophys. Res., 107(B12), 2357, doi:10.1029/2001JB001664, 2002.

U.S. Geological Survey, USGS WPhase Moment Solution, http://earthquake.usgs.gov/earthquakes/eqinthenews/2011/usc0001xgp/ neic_c0001xgp_wmt.php, accessed 7 April 2011, 2011.

T. Maeda (e-mail: maeda@eri.u-tokyo.ac.jp), T. Furumura, S. Sakai, and M. Shinohara 